\title{
Research Article \\ BIOCONTROL ACTIVITY OF YEAST STRAINS ISOLATED FROM GREEN COFFEE BEANS AGAINST OCHRATOXIN A-PRODUCING Aspergillus SPECIES
}

\author{
PAULUK-CORREA I. ${ }^{*}$, BOZZA DE ALMEIDA A. AND PIMENTEL I.C. \\ Basic Pathology Department, Federal University of Paraná, Street Francisco H. dos Santos, Curitiba, Paraná, 81530-900, Brazil \\ *Corresponding Author: Email - isabelapauluk@gmail.com
}

Received: May 29, 2018; Revised: June 15, 2018; Accepted: June 16, 2018; Published: June 30, 2018

\begin{abstract}
Coffee is one of the most consumed products worldwide, but when not properly processed, it can be contaminated with ochratoxin A(OTA)-producing fungi such as Aspergillus species. The yeasts Wickerhamomyces anomalus, Meyerozyma guilliermondii, Meyerozyma caribbica, Hyphopichia burtonii, and Aureobasidium pullulans were isolated from green coffee beans and co-inoculated with the OTA-producing fungi Aspergillus ochraceus and Aspergillus carbonarius. Growth inhibition in vivo and in vitro as well as OTA levels were assessed. W. anomalus, $M$. caribbica, and $H$. burtonii had the best results. These yeasts have the potential to inhibit growth and reduce OTA production by fungi naturally occurring in coffee beans.
\end{abstract}

Keywords- Mycotoxins, Wickerhamomyces anomalus, Hyphopichia burtonii, Coffea arabica, Volatile compounds

Citation: Pauluk-Corrêa I., et al., (2018) Biocontrol Activity of Yeast Strains Isolated from Green Coffee Beans Against Ochratoxin A-Producing Aspergillus Species. International Journal of Microbiology Research, ISSN: 0975-5276 \& E-ISSN: 0975-9174, Volume 10, Issue 6, pp.-1268-1273. DOI: http://dx.doi.org/10.9735/0975-5276.10.6.1268-1273

Copyright: Copyright@2018 Pauluk-Corrêa I., et al., This is an open-access article distributed under the terms of the Creative Commons Attribution License, which permits unrestricted use, distribution and reproduction in any medium, provided the original author and source are credited.

Academic Editor / Reviewer: Jason Lee Furuie

\section{Introduction}

Coffee is one of the most important commodities in the world market, especially for subtropical countries [1]. Arabica coffee accounts for the majority of the global production, and the dry method is frequently used in coffee processing [1]. Studies comparing different post-harvest practices indicate that $92 \%$ of the beans processed using this method were contaminated with fungi [2]. This happens because bark and mucilage are not separated from ripe coffee beans while drying directly in the sun, and thus contamination can occur since coffee mucilage provides a good substrate for many microorganisms [3,4]. Several microorganisms have been isolated from coffee beans in many stages of maturation, such as fungi, yeasts, and bacteria [5-8]. Among them are fungi of the genera Aspergillus and Penicillium, which can produce ochratoxin A (OTA), a secondary metabolite that naturally occurs in nature and can be produced during storage in response to changes in temperature and moisture or addition of $\mathrm{H}_{2} \mathrm{O}_{2}$ [9-11]. OTA is nephrotoxic, hepatotoxic and a potentially carcinogenic, being related to the Balkan endemic nephropathy (irreversible and fatal kidney disease) [12]. OTA is commonly found in foods, such as grapes, cacao and coffee besides it is resistant to high temperatures, making it very difficult to control [13-17]. The presence of OTA in coffee is a result of post-harvest and storage conditions, as well as drying and transportation processes [18]. However, the use of chemicals to inhibit the growth of OTA-producing fungi and OTA contamination in foods has been banned in several countries [19]. In this scenario, yeasts produce secondary metabolites that arise as alternatives to control potentially toxigenic fungi during pre and postharvest processes [20]. This is mostly due to their ability to grow in harsh conditions such as high and low pH, and long periods under dry and anaerobic conditions [21, 22]. Thus, in this study, the objective was to assess the ability of yeast to inhibit OTA production and growth of Aspergillus species. To this end, we isolated yeast strains from green coffee beans and used in vitro and in vivo inhibition methods.

\begin{abstract}
Materials and Methods
Cultures

Yeast strains were isolated from green Coffea arabica beans collected in 2011 in Agronomic Institute of Paraná, located in Londrina, PR, Brazil. Green coffee beans were processed by the dry method, collected aseptically, and stored in sterile plastic bags protected from sunlight. The reference strain of OTA-producing Aspergillus ochraceus, INCQS 40013 (ATCC 22947), was obtained from the National Institute of Quality Control in Health (INCQS) of the Oswaldo Cruz Foundation, Rio de Janeiro, Brazil and the strain of OTA-producing Aspergillus carbonarius 187 UEL was provided by the Laboratory of Molecular Biology of the Londrina State University, Londrina, Brazil. Yeasts and fungi were stored at $4^{\circ} \mathrm{C}$.
\end{abstract}

\section{Culture media}

Four media were used in this study: Sabouraud agar (SB), Czapek Dox agar (CZA), Coffee agar (CA) and YEPD-MB-Phosphate Citrate Buffer agar (YEPD). The former was used for the isolation and inhibition tests and consisted of $40 \mathrm{~g} / \mathrm{L}$ glucose, $15 \mathrm{~g} / \mathrm{L}$ peptone, $10 \mathrm{~g} / \mathrm{L}$ agar. CZA was used in inhibition tests and consisted of $30 \mathrm{~g} / \mathrm{L}$ of sucrose, $2 \mathrm{~g} / \mathrm{L}$ of sodium nitrate, $1 \mathrm{~g} / \mathrm{L}$ of dipotassium phosphate, $0.5 \mathrm{~g} / \mathrm{L}$ of magnesium sulfate, $0.5 \mathrm{~g} / \mathrm{L}$ of potassium chloride, $0.01 \mathrm{~g} / \mathrm{L}$ of iron sulfate and $15 \mathrm{~g} / \mathrm{L}$ of agar.

CA was used in inhibition tests and was prepared by boiling $20 \mathrm{~g}$ of green coffee beans in 1 liter of water, which was then filtrated with a $0.45 \mathrm{~mm}$ filter. The water collected was mixed with $15 \mathrm{~g} / \mathrm{L}$ of agar. The YEPD was used in metabolite production detection and was prepared using $10 \mathrm{~g} / \mathrm{L}$ yeast extract, $20 \mathrm{~g} / \mathrm{L}$ peptone, $20 \mathrm{~g} / \mathrm{L}$ dextrose, $0.01 \mathrm{~g} / \mathrm{L}$ methylene blue, $0.1 \mathrm{M}$ Phosphate Citrate Buffer until pH 4 and $20 \mathrm{~g} / \mathrm{L}$ agar. 


\section{Yeast isolation}

Microorganisms from green coffee bean samples were isolated by direct plating of four beans on SB and incubated at $28^{\circ} \mathrm{C}$ for $72 \mathrm{~h}$. Yeast colonies were collected and purified for further identification and stored at $4^{\circ} \mathrm{C}$ [23]. Isolates were then deposited in the Coleções de Culturas Microbiológicas da Rede Paranaense CMRP rede TAXonline (Federal University of Paraná, Brazil).

\section{Yeast identification}

DNA extraction from yeast cells was performed from pure cultures incubated at $28^{\circ} \mathrm{C}$ for $48 \mathrm{~h}$, samples were diluted to $20 \mathrm{ng} / \mu \mathrm{L}$ [24]. For identification of yeasts, the ITS1-5.8S-ITS2 region of ribosomal DNA was amplified using the following primers: ITS1 (5' TCCGTAGGTGAACCTGCGG $\left.3^{\prime}\right)$ and ITS4 TCCTCCGCTTATTGATATGC 3'). DNA amplification was carried out in a $25 \mu \mathrm{L}$ volume, and each reaction contained 1x buffer, $2.5 \mathrm{mM} \mathrm{MgCl} 2,0.2 \mathrm{mM}$ dNTPs, $0.1 \mu \mathrm{M}$ each primer (ITS1 and ITS4) and $0.1 \mu \mathrm{M}$ Taq DNA polymerase (Applied Biosystems, USA) [25]. The PCR reaction was performed in an automatic thermal cycler (2720, Applied Biosystems) under the following conditions: initial denaturation at $94^{\circ} \mathrm{C}$ for $2 \mathrm{~min} ; 30$ cycles at $94^{\circ} \mathrm{C}$ for $35 \mathrm{sec}, 52^{\circ} \mathrm{C}$ for $30 \mathrm{sec}$ and $72^{\circ} \mathrm{C}$ for $1 \mathrm{~min}$; and final extension at $72^{\circ} \mathrm{C}$ for $7 \mathrm{~min}$. The PCR fragments were sequenced with an $\mathrm{ABI} 3500$ automated sequencer (Applied Biosystems).

\section{Growth inhibition tests of Aspergillus species \\ Inhibitory effect of yeasts in SB, CZA and CA}

Yeasts were inoculated in the three cultures media for 48 hours at $28^{\circ} \mathrm{C}$ and then transferred to tubes containing $0.85 \%$ saline solution at a cell concentration of $1 \times 10^{6}$ cells $/ \mathrm{mL}$ (estimated using a counting chamber). A. ochraceus and $A$. carbonarius were inoculated for 7 days at $28^{\circ} \mathrm{C}$. One milliliter of yeast suspension was added to $5 \mathrm{~mL}$ of the melted culture medium where the yeast was inoculated, and the suspension was spread over a sterile Petri dish containing $15 \mathrm{~mL}$ of the same culture medium. A 4-mm diameter disc was removed from the center of each plate and $10 \mu \mathrm{L}$ of a suspension of $A$. ochraceus or $A$. carbonarius $\left(1 \times 10^{6}\right.$ spores $/ \mathrm{mL}$ ) was added. The tests plates were incubated for 7 days at $28^{\circ} \mathrm{C}$, and the growth of Aspergillus sp. was evaluated. The assay was carried out with three repetitions and the control group consisted of plates containing only the standards of $A$. ochraceus and A. carbonarius [20]. The diameter of the Aspergillus sp. colonies was measured to determine growth inhibition using the formula

$$
(\mathrm{PI} \%)=((\mathrm{Dc}-\mathrm{Dt}) / \mathrm{Dc}) \times 100
$$

Where, Dt as the diameter of the colony of Aspergillus sp. in the inhibition test and Dc the diameter of the control group of Aspergillus sp. [26].

\section{Reduction of OTA production by Aspergillus species}

Yeasts were inoculated for 48 hours at $28^{\circ} \mathrm{C}$ then transferred to tubes containing $0.85 \%$ saline solution $\left(1.5 \times 10^{8} \mathrm{cell} / \mathrm{sL}\right)$ and spread on SB plates [27]. A $7 \mathrm{~mm}$ disc was removed from the center of each plate, and a SB disc containing Aspergillus mycelia incubated for 7 days at $28^{\circ} \mathrm{C}$ was inserted. The experiments were carried out with three repetitions for 7 days at $28^{\circ} \mathrm{C}$, and plates containing only Aspergillus mycelia were used as control. Three small aliquots ( $7 \mathrm{~mm}$ plugs) of fungi were collected and transferred to tubes containing $1.5 \mathrm{~mL}$ of methanol. The suspensions were placed for one hour in the dark and then centrifuged at $4000 \mathrm{rpm}$. The toxin was filtered through glass wool and evaporated at $50^{\circ} \mathrm{C}$ and added $1 \mathrm{~mL}$ of the mobile phase of the HPLC (SYS-LC-240-E, Varian, USA), acetonitrile: acidified water (2\%) (50:50 (v:v)) filtered through a 0.22- $\mu \mathrm{m}$ pore filter $[28,29]$. The samples were analyzed by HPLC with fluorescence detection (330 $\mathrm{nm}$ excitation and $470 \mathrm{~nm}$ emission) (Fluorescence detector model 363, Varian, USA), using a C18 column ( $5 \mu \mathrm{m}, 25 \times 4.6 \mathrm{~mm}$, Varian, USA) a full loop was injected though a ProStar 410 Auto-Sampler at a flow rate of $1 \mathrm{~mL} / \mathrm{min}$. The concentrations were expressed in $\mathrm{ng} / \mathrm{L}$, and the detection limit of this method was $0.5 \mathrm{ng} / \mathrm{L}$, the default OTA values for $A$. carbonarius and $A$. ochraceus were established by extracting the toxin of standard strains. The experimental data were expressed as percentages of inhibition, according to the following formula:

$$
\% \text { Reduction }=100-[(\text { Cota sample } / \text { Cota control }) \times 100][30] .
$$

\section{Investigation of the mechanism inhibition} Inhibitory effect of volatile compounds produced by yeasts

Yeasts and fungi were inoculated in SB, incubated for 48 hours (yeasts) and 7 days (fungi) at $28^{\circ} \mathrm{C}$, then transferred to tubes containing $0.85 \%$ saline solution to obtain suspensions at the concentrations of $1 \times 10^{6} \mathrm{cells} / \mathrm{mL}$ and $1 \times 10^{6} \mathrm{spores} / \mathrm{mL}$. Yeast suspensions $(100 \mu \mathrm{L})$ were spread on SB plates, while in another SB plate a $4 \mathrm{~mm}$ disc was removed from the center and $10 \mu \mathrm{L}$ of the suspension of A. ochraceus or $A$. carbonarius was added. Plates were fitted to each other and sealed to prevent the leakage of volatile compounds produced by yeasts. Plates were incubated at $28^{\circ} \mathrm{C}$ for 14 days, and the growth of Aspergillus sp. was measured at 7 and 14 days of testing [20]. The assay was carried out with three repetitions and control plates containing only Aspergillus sp. were used. The diameter of Aspergillus sp. colonies was measured to determinate growth inhibition with the formula [item 2.5.1].

\section{Detection of production of metabolites by yeasts}

The yeasts were inoculated in the media YEPD-MB-Phosphate Citrate Buffer-Agar with conditions that enable the metabolite production to assay the capability of those to produce metabolites [31]. An $6 \mathrm{~mm}$ agar plug with a 2 days colony were placed in a plate containing the YEPD media. After 2 days the color of the media was analyzed and clear halos were indicative of metabolite production.

\section{Analysis of the inhibitory potential of selected yeast in vivo in green coffee beans against Aspergillus sp. \\ Inoculum preparation}

The yeast with the highest in vitro inhibition rates, W. anomalus - CAT 1 L1 inoculated for 48 hours and Aspergillus sp. for 7 days on SB plates were selected for the in vivo tests and transferred to tubes containing $0.05 \%$ of Tween 80 . The concentrations were standardized in $1 \times 10^{5}$ and $1 \times 10^{7}$ cells $/ \mathrm{mL}$ for yeast, and $1 \times 10^{2}$ spores/mL for Aspergillus sp. [32].

\section{Coffee beans preparation}

The grains must undergo a superficial disinfection to avoid contamination. Three hundred grams of green coffee beans were disinfected with autoclaved water, alcohol (70\%), and hypochlorite (3.5\%) in a laminar flow hood, where they remained drying on a sterile paper filter for 1 hour [32].

\section{Inoculation in green coffee beans}

Beans were immersed in $500 \mathrm{~mL}$ of yeast suspension for 2 minutes. For the negative control, beans were immersed for 2 minutes in $500 \mathrm{~mL}$ of $0.05 \%$ tween 80. After drying in a laminar flow hood, $5 \mathrm{~mL}$ of Aspergillus $\mathrm{sp}$. suspension was sprayed on coffee beans that were then dried on a sterile filter paper. Tests were carried out with three repetitions, beans were placed in jute bags and incubated in the dark at $26^{\circ} \mathrm{C}$ and $75 \%$ humidity for 24 days [32]. The growth of Aspergillus sp. was evaluated every 2 days by collecting 10 grams of coffee beans and examining under stereoscope (Zeiss, Germany). Aspergillus sp. growth was expressed as percentages. The temperature was standardized at $26^{\circ} \mathrm{C}$ (temperature at which the grains are normally stored in the field). The following moisture conditions were tested in the incubation of the grains, $0 \%$ (no microorganism proliferation) and $90 \%$.

\section{Statistical analysis}

Analysis of Variance (ANOVA) was performed using a completely randomized design (DIC). When significant differences were detected by the $F$ test, the analyzes were followed by the Tukey test $(p<0.01)$ using the statistical software ASSISTAT version 7.7 [33].

\section{Results and Discussion \\ Yeast isolation and identification}

Thirteen yeast isolates were obtained from green coffee bean samples and identified as Wickerhamomyces anomalus, Hyphopichia burtonii, Meyerozyma caribbica, Aureobasidium pullulans, and Meyerozyma guilliermondii [Table-1]. This is the first report on the isolation of A. pullulans on green coffee beans. 
Table-1 Yeast strains isolated from green coffee beans and identified by sequencing the ITS1-5.8S rDNA-ITS2 region amplified with primers ITS1 and ITS4, the GenBank accession number and Coleção de Culturas Microbiológica da Rede Paranaense -CMRP accession number.

\begin{tabular}{|c|c|c|c|c|c|}
\hline Strain ID & Species & $\begin{array}{l}\text { Amplicon size } \\
\text { (bp) }\end{array}$ & Identity ${ }^{1}(\%)$ & $\begin{array}{c}\text { GenBank } \\
\text { Accession No. }\end{array}$ & $\begin{array}{c}\text { CMRP Accession } \\
\text { No. }\end{array}$ \\
\hline CAT 1 L1 & Wickerhamomyces anomalus & 593 & 99 & KP638728 & CMRP3421 \\
\hline 1033 L1 & Wickerhamomyces anomalus & 570 & 99 & KP638741 & CMRP3422 \\
\hline $1021 \mathrm{~L} 2 \mathrm{~B}$ & Hyphopichia burtonii & 443 & 99 & KP638740 & CMRP3423 \\
\hline $1022 \mathrm{~L} 2$ & Hyphopichia burtonii & 432 & 97 & KP638737 & CMRP3424 \\
\hline $1022 \mathrm{~L} 1$ & Hyphopichia burtonii & 443 & 99 & KP638729 & CMRP3425 \\
\hline $1021 \mathrm{~L} 1$ & Hyphopichia burtonii & 403 & 99 & KP638735 & CMRP3426 \\
\hline CAT 2 L1 & Meyerozyma caribbica & 607 & 99 & KP638738 & CMRP3427 \\
\hline 1023 L1 & Meyerozyma caribbica & 607 & 100 & KP638733 & CMRP3428 \\
\hline 1043 L1 & Aureobasidium pullulans & 582 & 98 & KP638730 & CMRP3429 \\
\hline $1063 \mathrm{~L} 2$ & Aureobasidium pullulans & 582 & 99 & KP638731 & CMRP3430 \\
\hline $1021 \mathrm{~L} 2 \mathrm{~N}$ & Aureobasidium pullulans & 535 & 99 & KP638732 & CMRP3431 \\
\hline 1043 L2 & Aureobasidium pullulans & 584 & 99 & KP638734 & CMRP3432 \\
\hline $1071 \mathrm{~F} 1$ & Meyerozyma guilliermondii & 616 & 99 & KP638727 & CMRP3433 \\
\hline
\end{tabular}

${ }^{1}$ Percentage of identical nucleotides found in GenBank sequences

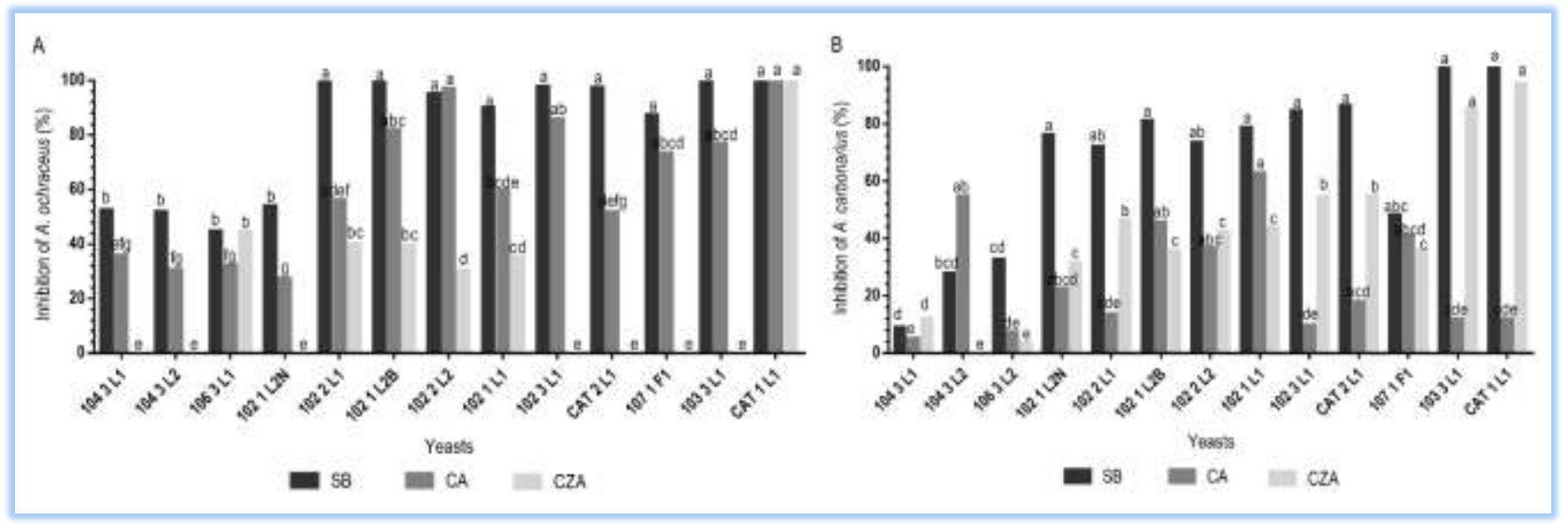

Fig-1 Percentages of inhibition of $A$. ochraceus and (A) A. carbonarius (B) in SB, CA, and CZA. 'Different letters in the same medium indicate significant differences detected by the Tukey test $(P<0.01)$.

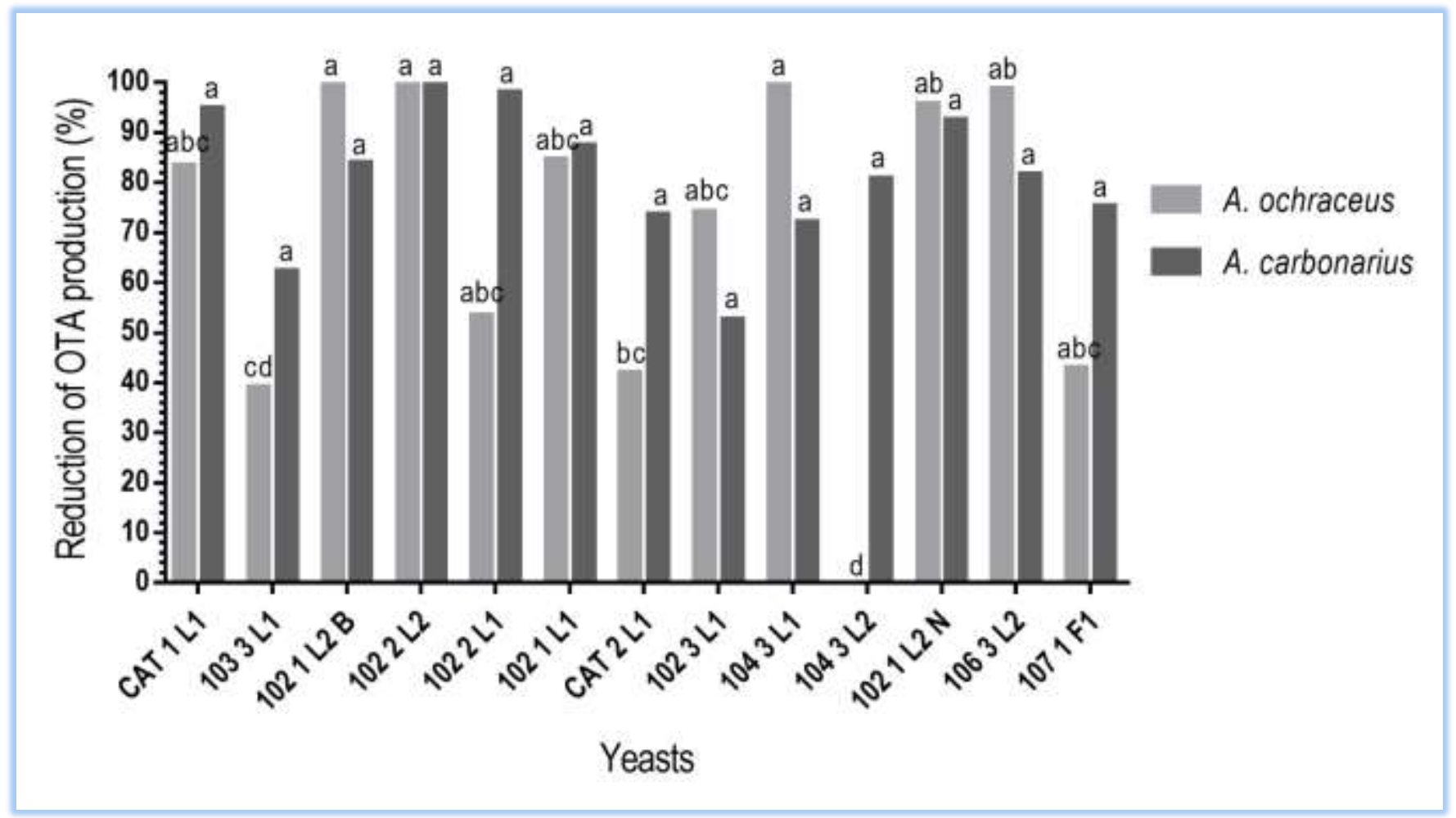

Fig-2 Reduction of Aspergillus-produced OTA by yeast isolated from green coffee beans. Reduction of OTA was expressed in percentage compared to the control. ${ }^{1}$ Different letters indicate significant differences, according to the Tukey test for each Aspergillus species $(P<0.01)$. 
A

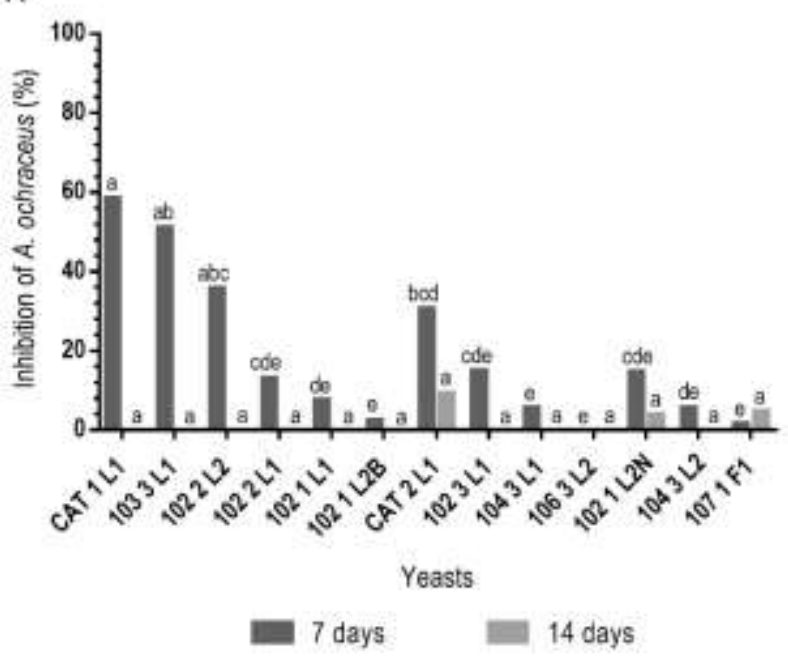

B

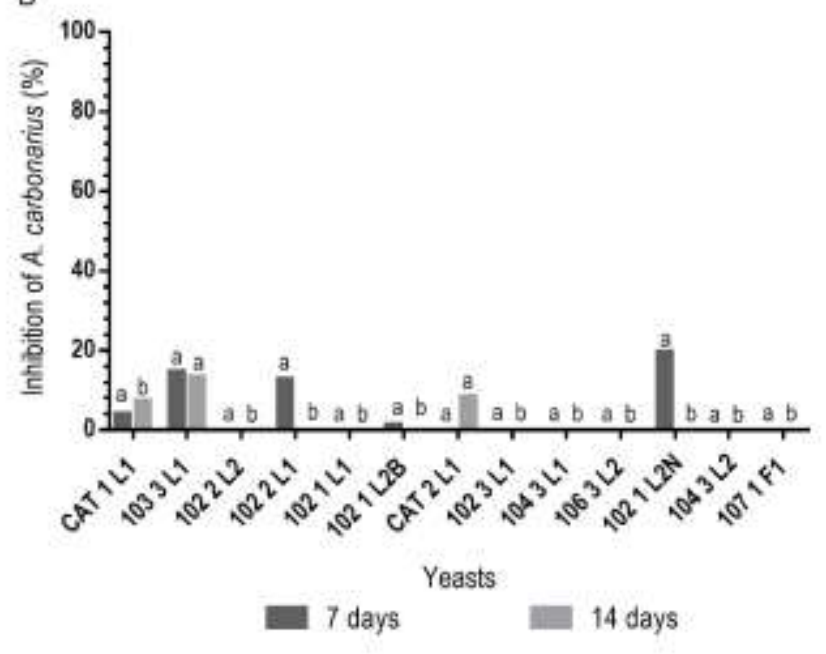

Fig-3 Percentages of inhibition of $A$. ochraceus (A) and A. carbonarius (B) by volatile compounds produced by yeast isolates. ${ }^{1}$ Different letters indicate significant differences of each period by the Tukey test $(\mathrm{P}<0.01)$.
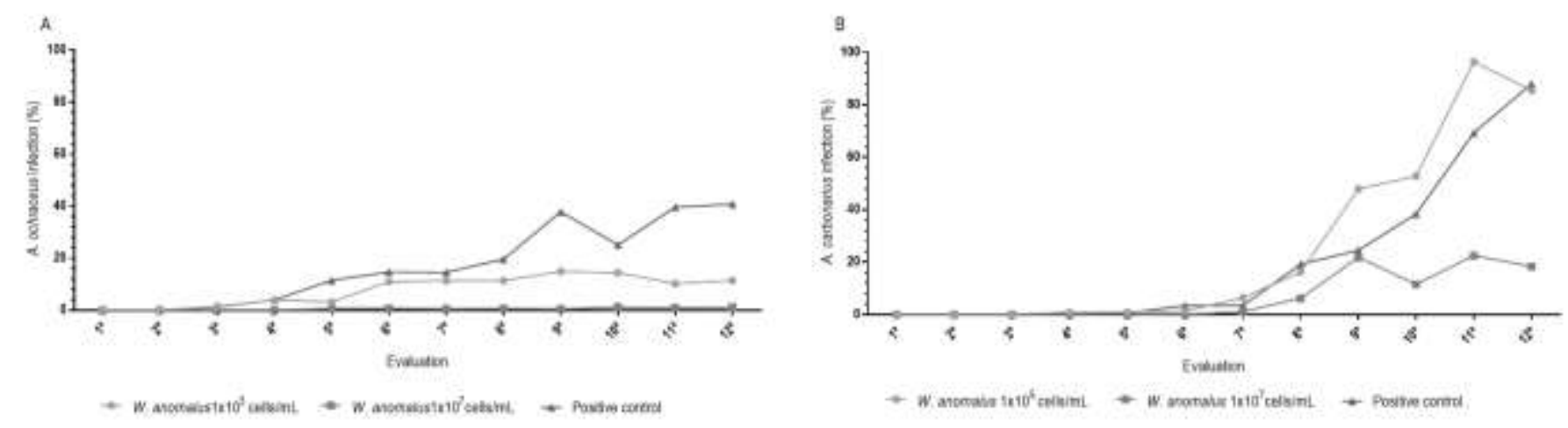

Fig-4 Infection percentage of $A$. carbonarius (A) and A. ochraceus (B) in coffee beans inoculated with W. anomalus.

The yeasts M. guilliermondii, W. anomalus and $H$. burtonii have been previously isolated from Brazilian coffee beans in different stages of processing [34]. M. caribbica was found in small amounts in coffee beans processed by a semi-dry method [35]. Hamadi et al. [36] isolated yeasts from Tanzanian coffee beans processed by the wet method that were capable of fermenting ethanol, among them M. guilliermondii and W. anomalus, indicating their potential in bioethanol production.

\section{Growth inhibition tests of Aspergillus species Inhibitory effect of yeasts in SB, CZA and CA medium.}

All thirteen yeast isolates were able to inhibit Aspergillus species in at least one culture medium [Fig-1]. Our results showed that the inhibition percentage of A. ochraceus (mean of $82.29 \%$ for SB, $62.15 \%$ for CA, and $22.23 \%$ for CZA) was higher than the inhibition of $A$. carbonarius (mean $66.89 \%$ for $\mathrm{SB}, 26.29 \%$ for $\mathrm{CA}$ and $41.43 \%$ for CZA), in agreement with the findings by Zhu et al. [20]. The best results were obtained using $S B$, with inhibition varying between 44.65 and $100 \%$ for A. ochraceus and 8.95 to $100 \%$ for $A$. carbonarius. Regarding CZA, inhibition was highest for $A$. carbonarius (ranging from 3.45 to $93.84 \%$ ), with the best results were obtained using $W$. anomalus (93.84\% for CAT 1 L1 and $85.13 \%$ for 1033 L1). For CA, A. carbonarius inhibition was highest with $H$. burtonii (102 1 L1), while for $A$. ochraceus, inhibition was highest with $W$. anomalus (CAT 1 L1). Culture media with high carbon concentration (SB) induce yeast growth, consequently inhibiting $A$. ochraceus and $A$. carbonarius [28]. Comparing our results on $C A$ and CZA, A. ochraceus inhibition was highest using the former, suggesting that yeasts grown better in an environment similar to the one they were isolated from. Studies show that the caffeine can control the grow of yeasts, this can be confirmed by the inhibition results when CA produce less inhibition comparing with SB [37]. SB had the highest carbon concentration compared to those of other media used and had the best results. A high nutrient level promotes yeasts grow and consequently Aspergillus inhibition, thus SB was used in the tests.

\section{Reduction of OTA production by the Aspergillus species}

The yeast isolates evaluated decreased OTA levels produced by $A$. ochraceus and $A$. carbonarius. The reduction of OTA levels produced by $A$. ochraceus ranged from 42.06 to $100 \%$ [Fig-2]. The highest percentages of OTA reduction were obtained for the yeasts $H$. burtonii (102 $2 \mathrm{~L} 2$ and $1021 \mathrm{~L} 2 \mathrm{~B}$ ) and $\mathrm{A}$. pullulans (104 3 L1). OTA reduction was highest for $A$. carbonarius, with a mean of $76.15 \%$, while lower reduction rates were observed for $A$. ochraceus (mean of $69.01 \%$ ). Studies evaluating OTA degradation by yeasts have found that $A$. pullulans degrades OTA into OTa, a less toxic compound and phenylalanine [38]. Candida intermedia, Candida friedrichii, and Lachancea thermotolerans degrade OTA in grape juice up to $75 \%$, while M. guilliermondii degraded $65.3 \%$ of OTA added to a liquid media $[39,40]$. Other yeasts can decrease OTA production by inhibiting fungal growth, such as $W$. anomalus and $P$. kluyveri against $A$. ochraceus [28]. Other hand, some yeasts, such as Candida zemplinina and Saccharomyces cerevisiae, could not degrade OTA after it was produced [20]. The yeast isolates tested were able to reduce OTA production, possibly by inhibiting fungal growth, absorbing the toxin, or producing substances diffusible in the media that can degrade OTA, possibly into OTa and phenylalanine [41, 42]. Further studies should be conducted to investigate the mechanisms associated to OTA reduction. 
No studies have reported the reduction of OTA production by $H$. burtonii and M. caribbica. The yeast $W$. anomalus (CAT 1 L1) showed significant inhibitory potential in in vitro tests and was selected for in vivo testing.

\section{Investigation of the mechanism inhibition}

\section{Inhibitory effect of volatile compounds produced by yeasts}

Yeast isolates produced volatile compounds that inhibited the growth of A. ochraceus and $A$. carbonarius. Inhibition rates were highest for $W$. anomalus (CAT 1 L1) against $A$. ochraceus at 7 days (58.2\%). No statistically significant differences between the inhibition of $A$. carbonarius were found at 7 days. Two yeasts were statistically superior to the other yeasts [Fig-3] at 14 days testing, W. anomalus (8.38\%) (CAT 2 L1) and M. caribbica (11.33\%) (103 3 L1). Volatile compounds produced by yeasts have low-molecular weight and thus can easily evaporate at normal temperature and pressure conditions [43]. In our study, volatile compounds of yeasts inhibited Aspergillus species, and according to Hua et al. (2014) [44], they can affect spore germination, mycelial growth, toxin production and gene expression. Studies have shown that $A$. ochraceus is inhibited by volatile yeast compound especially those produced by $W$. anomalus, which induced the highest inhibition rates, compared to $P$. kluyveri and Hanseniaspora uvarum [45]. Parafati, et al. (2017) [46] used volatile compounds of $W$. anomalus and $A$. pullulans against $B$. cinerea, $P$. digitatum, and $P$. italicum. After direct contact between a suspension of yeast and fungus, conidial germination was evaluated, revealing that $W$. anomalus strongly inhibited spore germination of the 3 fungi tested (percentage of germination below $7 \%$ ), A. pullulans also inhibited fungi growth, but with higher percentages of germination.

\section{Detection of production of metabolites by yeasts}

Six yeasts (107 1 F1, 103 3 L1, CAT 1 L1, 1063 L2, 1043 L2, 1022 L1) shown to be able to produce metabolite. M. guilliermondii, W. anomalus, A. pullulans, $H$. burtonii. Studies indicate that M. guilliermondii presents metabolite extracted with ethyl acetate with inhibitory activity against bacteria [47]. W. anomalus has the ability to produce volatile secondary metabolites such as ethyl acetate, isoamyl acetate and ethyl propionate [21, 45]. A. pullulans produces in its metabolism the pullulan substance that has enormous application in the alimentary area, such as stimulatory effect on insulinotropic activity of pancreatic islets [48]. No data are available on the production of metabolites by $H$. burtonii. These results indicate that yeasts have the ability to produce metabolites of interest, further tests should be performed to assess whether they have antimicrobial capacity.

\section{Analysis of the inhibitory potential of selected yeast in vivo in green coffee beans against Aspergillus sp.}

The infection percentage of $A$. ochraceus or $A$. carbonarius in stored coffee beans was calculated by evaluating fungal growth [Fig-4]. The results indicated that W. anomalus (CAT $1 \mathrm{~L} 1$ ) in both concentrations used was effective in inhibiting A. ochraceus during the 24 days tested, when compared to the positive control. The growth rate of $A$. ochraceus was $40 \%$ for the positive control and $11 \%$ in the test with yeast at the concentration of $105 \mathrm{cell} / \mathrm{s} / \mathrm{ml}$ and $1.26 \%$ for the test using the yeast at the concentration of $10^{7}$ cells $/ \mathrm{mL}$. Yeast isolates inoculated at the concentration of $1 \times 10^{7}$ cells $/ \mathrm{mL}$ induced the highest reduction in $A$. ochraceus growth. Regarding $A$. carbonarius infection, fungal growth was $25 \%$ when yeast was inoculated the concentration of $1 \times 10^{5}$ cells $/ \mathrm{mL}$, and at a higher concentration $\left(1 \times 10^{7}\right.$ cells $\left./ \mathrm{mL}\right)$ A. carbonarius was inhibited with growth rate at $6 \%$. Comparing the growth rate of $A$. carbonarius in the positive control $(20 \%)$ and in the test with yeast at the concentration of $10^{5} \mathrm{cell} / \mathrm{s} / \mathrm{mL}(25 \%)$, it is observed that the yeast concentration was not sufficient to inhibit the fungus, this concentration may still have generated a stress condition for the fungus, which may have led to an induction of OTA production. Studies indicate that the otapksPV gene (related to OTA production) is regulated by environmental stimulation, suggesting that the inhibition did not occur at this concentration because the fungus may have produced OTA, causing damage to yeast $[49,50]$. Yeast isolates from green coffee beans are promising alternatives to inhibit mycotoxin-producing fungi in vivo, as they can prevent OTA production and are already used in coffee fermentation $[6,51]$. The inoculation of these yeasts in stored coffee beans does not alter the quality of coffee and can prevent the proliferation of fungi under storage conditions [52]. Also, they easily grow in liquid media, making large-scale production viable. Further studies are needed to identify the active metabolites of yeast isolates and apply them to inhibit Aspergillus spp. in stored coffee beans.

\section{Conclusion}

Our results indicate that yeast isolates from green coffee beans clearly inhibited A. ochraceus and $A$. carbonarius growth (in vivo and in vitro) and OTA production. $A$ high yeast concentration is required to inhibit fungal growth in coffee beans. We demonstrated that the yeasts, especially $W$. anomalus, have the potential to be used as biocontrol agents.

Application of research: These results indicate that yeasts isolated from coffee beans and their products (volatile and non-volatile) can be used to control fungi OTA-producers in stored coffee bean. Those results can be an alternative for the using of chemical products.

\section{Research Category: Applied and Environmental Microbiology; Food Microbiology}

Abbreviations: Ochratoxin A (OTA), Sabouraud agar (SB), Czapek Dox agar (CZA), Coffee agar (CA), YEPD-MB-Phosphate Citrate Buffer agar (YEPD), Analysis of Variance (ANOVA).

Acknowledgements/Funding: We thank the IAPAR and Maria Brigida dos Santos Scholz (IAPAR, Londrina, Brazil) for the donation of the coffee beans and João Guilherme Rodenbusch Destro for the assistance in yeast isolation. The authors are grateful to Maria da Graça Toledo (Analytical Central, Pharmaceutical Sciences, UFPR, Brazil) for the assistance in HPLC analysis, the National Council for Scientific and Technological Development (CNPq) for grant scholarship to the authors, the Oswaldo Cruz Foundation and the Molecular Biology Laboratory of State University of Londrina and Maria Helena Fungaro for the donation of the standard strains. We also thank the company Café Atributo for the donation of the green coffee beans.

\section{*Principle Investigator: Isabela Pauluk Corrêa \\ University: Federal University of Paraná \\ Research project name or number: Avaliação de leveduras no controle pós- colheita de Aspergillus sp. em grãos de café}

\section{Author Contributions: All author equally contributed}

Author statement: All authors read, reviewed, agree and approved the final manuscript

\section{Conflict of Interest: None declared}

Ethical approval: This article does not contain any studies with human participants or animals performed by any of the authors.

\section{References}

[1] ICO - International Coffee Organization. (2016) Exports of all forms of coffee by all exporting countries. URL http://www.ico.org/historical/1990\%20onwards/PDF/2a-exports.pdf. Accessed 09/05/2017.

[2] Suárez-Quiroz M., González-Rios O., Barel M., Guyot B., SchorrGalindo S. and Guiraud J. (2004) International Journal of Food Science and Technology, 39(5), 501-07.

[3] Silva C. F., Schwan R. F., Dias E. S. and Wheals A. E. (2000) International Journal of Food Microbiology, 60(2-3), 251-60.

[4] Sivetz M. and Foote H. E. (1963) The Avi Publishing Company, 48-99. 
[5] lamanaka B. T., Teixeira A. A., Teixeira A. R. R., Copetti M. V., Bragagnolo N. and Taniwaki M. H. (2014) Food Research International, 62, 353-58.

[6] Pereira G. V. M., Soccol V. T., Pandey A., Medeiros A. B. P., Lara J. M. R. A., Gollo A. L. and Soccol C. R. (2014) International Journal of Food Microbiology, 188(1), 60-66.

[7] Silva C. F., Vilela D. M., Cordeiro C. S., Duarte W. F., Dias D. R. and Schwan R. F. (2013) World Journal of Microbiology \& Biotechnology, 29(2), 235-47.

[8] Taniwaki M. H., Teixeira A. A., Teixeira A. R. R., Copetti M. V. and lamanaka B. T. (2014) Food Research International, 61, 161-66.

[9] Whitfield F. B. (1998) International Journal of Food Science and Technology, 33(1), 31-51.

[10] Abrunhosa L., Paterson R. R. M. and Venâncio A. (2010) Toxins, 2(5), 1078-99.

[11] Subramaniam R. and Rampitsch C. (2013) Toxins, 5(4), 675-82.

[12] Castegnaro M., Bartsch H. and Chernozemsky I. (1987) Cancer Research, 47, 3608-09.

[13] Romani S., Sacchetti G., Chaves Lopez C., Pinnavaia G. G. and Dalla Rosa M. (2000) Journal of Agricultural and Food Chemistry, 48(8), 3616-19.

[14] Tafuri A., Ferracane R. and Ritieni A. (2004) Food Chemistry, 88(4), 487-94.

[15] EFSA (European Food Safety Authority). (2006) The EFSA Journal, 365, 1-56.

[16] FAO - Food and agriculture organization of the united nations. (2006). Enhancement of Coffee Quality through the Prevention of Mould Formation.http://www.fao.org/fileadmin/user_upload/agns/pdf/coffee/FTR200 6.pdf. Accessed 03/05/2017.

[17] Serra R., Mendonca C. and Venancio A. (2006) International Journal of Food Microbiology, 111(1), 35-39.

[18] Durand N., El Sheikha A. F., Suarez-Quiros M., Oscar G., Nganou N. D. and Fontana-Tachon A. (2013) Food Control, 34(2), 466-71.

[19] Zhang D., Spadaro D., Garibaldi A. and Gullino M.D. (2011) Biological Control, 57(3), 193-01.

[20] Zhu C., Shi J., Jiang C. and Liu Y. (2015) Food Control, 50, 125-32.

[21] Druvefors U., Passoth V. and Schnurer J. (2005) Applied and Environmental Microbiology, 71(4), 1865-69.

[22] Fredlund E., Druvefors U., Boysen M. E., Lingsten K. J. and Schnurer J. (2002) FEMS Yeast Research, 2(3), 395-02.

[23] Noonim P., Mahakarnchanakul W., Nielsen K. F., Frisvad J. C. and Samson R. A. (2008) International Journal of Food Microbiology, 128(2), 197-02.

[24] Badali H., Carvalho V. O., Vicente V., Attili-Angelis D., Wiatkowski I. B. and Van den Ende A. H. G. (2009) Medical Mycology, 47(1), 55-66.

[25] Masoud W., Cesar L.B., Jespersen L. and Jakobsen M. (2004) Yeast, 21(7), 549-56.

[26] Edginton L. V., Knew K. L. and Barron G. L. (1971) Phytopatology, 61, 42-44.

[27] NCCLS - National Committee for Clinical Laboratory Standards. (2003) Padronização dos Testes de Sensibilidade a Antimicrobianos por Disco-difusão: Norma Aprovada - Oitava Edição. URL http://www.anvisa.gov.br/servicosaude/manuais/clsi/c/si_OPASM2A8.pdf. Accessed 12/8/2017

[28] Masoud W. and Kaltoft C. H. (2006) International Journal of Food Microbiology, 106(2), 229-34.

[29] Taniwaki M. H., Pitt J. I., Teixeira A. A. and lamanaka B. T. (2003) International Journal of Food Microbiology, 82(2), 173-79.

[30] Kapetanakou A. E., Kollias J. N., Drosinos E. H. and Skandamis P. N. (2012) International Journal of Food Microbiology, 152(3), 91-99.

[31] Nally M. C., Pesce V. M., Maturano Y. P., Rodriguez Assaf L. A., Toro M. E., Castellanos L. I., and Vazquez F. (2015) International Journal of Food Microbiology, 204, 91-100.
[32] Paster N., Droby S., Chalutz E., Menasherov M., Nitzan R. and Wilson C.L. (1993) Microbiology Research, 97(10), 1201-06.

[33] Silva F. A. S. and Azevedo C. A. V. (2002) Revista Brasileira de Produtos Agroindustriais, 4(1), 71-78.

[34] Silva C. F., Batista L. R., Abreu L. M., Dias E. S. and Schwan R. F. (2008) Food Microbiology, 25(8), 951-57.

[35] Vilela D. M., Pereira G. V. M., Silva C. F., Batista L. R. and Schwan R. F. (2010) Food Microbiology, 27(8), 1128-35.

[36] Hamadi S., Muruke M. H. and Hosea K. M. M. (2014) International Journal of Life Sciences, 3(4), 213-21.

[37] Vega, F.E., Blackburn, M.B., Kurtzman, C.P., Dowd, P.F (2003) Entomologia Experimentalis et Apllicata, 107, 19-24.

[38] De Felice D. V., Solfrizzo M., De Curtis F., Lima G., Visconti A. and Castoria R. (2008) Phytopathology, 98(12), 1261-70.

[39] Fiori S., Urgeghe P. P., Hammami W., Razzu S., Jaoua S. and Migheli Q. (2014) International Journal of Food Microbiology, 189, 45-50.

[40] Patharajan S., Reddy K. R. N., Karthikeyan V., Spadaro D., Lore A., Gullino M. L. and Garibaldi A. (2011) Food Control, 22(2), 290-96.

[41] Abrunhosa L., Santos L. and Venâncio A. (2006) Food Biotechnology, 20(3), 231-42.

[42] Bejaoui H., Mathieu F., Taillandier P. and Lebrihi A. (2004) Applied Microbiology, 97(5), 1038-44.

[43] Wang C., Wang Z., Qiao X., Li Z., Li F., Chen M., Wang Y., Huang Y. and Cui H. (2013) FEMS Microbiology Letters, 341(1), 45-51.

[44] Hua S. S. T., Beck J. J., Sarreal S. B. L. and Gee W. (2014) Mycotoxin Research, 30(2), 71-78.

[45] Masoud W., Poll, L. and Jakobsen M. (2005) Yeast, 22(14), 1133-42.

[46] Parafati L., Vitale A., Restuccia C. and Cirvilleri G. (2017) Food Microbiology, 63, 191-98.

[47] Joel E. L., and Bhimba B. V. (2013) Alexandria Journal of Medicine, 49(3), 189-94.

[48] Singh R. S., Kaur N., Rana V., and Kennedy J.F. (2017) Carbohydrate Polymers, 171, 102-21.

[49] Schmidt-Heydt M., Baxter E., Geisen R., and Magan N. (2007) International Journal of Food Microbiology, 119(3), 277-83.

[50] Schmidt-Heydt M., Stool D., and Geisen R. (2013) International Journal of Food Microbiology, 166(3), 407-12.

[51] Pereira G. V. M., Beux M., Pagnoncelli M. G. B., Soccol V. T., Rodrigues C. and Soccol C. R. (2015) Letters of Applied Microbiology, 62(1), 96-101.

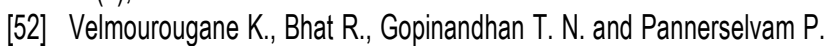
(2011) Biological Control, 57(3), 215-21. 